\section{MS score in systemic juvenile idiopathic arthritis: suitable for routine use?}

We read with great interest the article by Minoia $e t a l^{1}$ which reported a new scoring tool for the classification of macrophage activation syndrome (MAS), a potentially life-threatening complication requiring prompt treatment, in patients with systemic juvenile idiopathic arthritis (sJIA). Although the haemophagocytic lymphohistiocytosis diagnostic criteria were widely used, early diagnosis of MAS is still challenging. ${ }^{23}$ The creation of the MAS/sJIA (MS) score provided a new tool for early detection of MAS in sJIA. However, a few points of concern raised when using the MS score in our centre.

First, the data of patients with MAS were recorded at the onset of the syndrome while the clinical features of patients with active sJIA without MAS were collected at the onset or flare of the disease. Since exacerbation could occur at any point. As a result, data that were not collected at a single point in time might cause selection bias. The comparison might be more reasonable if the clinical data of both groups were recorded at the same disease status.

Besides, the central nervous system (CNS) dysfunction, the most important clinical feature included in the scoring formula, was defined as 'the presence of lethargy, seizures, irritability, confusion, headache, mood changes or coma'. The percentage of CNS involvement was much higher in patients with active sJIA with MAS (35\%) than those who did not have MAS in the article $(1.8 \%, \mathrm{p}<0.0001)$. The definition of headache and mood changes were not clarified. An ambiguous definition may cause variance in understanding these terms. For example, mood changes may refer to minor daily changes or to significant mood disturbances such as major depression or bipolar depression. And the mild headache is relatively common in feverish patients. We wonder if minor daily mood changes and mild headache were also counted as CNS dysfunction during MS score calculating.

What's more, took the presence of fever as a mandatory criterion for the diagnosis of MAS may lead to missed or delayed diagnosis. The body temperature might be under control by the initiation of glucocorticoids or other treatments such as interleukin-1 inhibitor, even if the occult MAS has already developed. Besides, they did not include sCD25 and natural killer cell activity during the score developing process because these tests were not routinely assessed in most paediatric rheumatology centres. However, both biomarkers are important objective indicators of increased $\mathrm{T}$ cell activation and impaired cytolytic function in the pathogenesis of MAS. ${ }^{4}$ The exclusion of these two parameters may affect the sensitivity and specificity of MAS detection. The MS score should be further validated in centres capable of completing the measurement of sCD25 and natural killer cell activity.

Though the performance of the MS score is quite well in the validation group, the application of MS score for the diagnosis of MAS in clinical practice is questionable in its current state.

Huihui Chi, ${ }^{\ominus}$ Zhihong Wang, Chengde Yang, Yutong Su ${ }^{\odot}$

Department of Rheumatology and Immunology, Shanghai Jiao Tong University Medical School Affiliated Ruijin Hospital, Shanghai Jiao Tong University School of Medicine, China

Correspondence to Dr Yutong Su and Prof Chengde Yang, Shanghai Jiao Tong University Medical School Affiliated Ruijin Hospital, Shanghai 200025, China; suyt2015@163.com, yangchengde@sina.com

Handling editor Josef S Smolen

Contributors HC: concept, writing; ZW: concept; CY: revising; YS: concept, revising.

Funding This work was supported by the National Natural Science Foundation of China (No. 81801600).

Competing interests None declared.

Patient consent for publication Not required.

Provenance and peer review Not commissioned; internally peer reviewed.

(C) Author(s) (or their employer(s)) 2019. No commercial re-use. See rights and permissions. Published by BMJ.

$$
\text { D) Check for updates }
$$

To cite Chi H, Wang Z, Yang C, et al. Ann Rheum Dis Epub ahead of print: [please include Day Month Year]. doi:10.1136/annrheumdis-2019-216041

Received 17 July 2019

Accepted 22 July 2019

Ann Rheum Dis 2019;0:1. doi:10.1136/annrheumdis-2019-216041

\section{REFERENCES}

1 Minoia F, Bovis F, Davi S, et al. Development and initial validation of the MS score for diagnosis of macrophage activation syndrome in systemic juvenile idiopathic arthritis. Ann Rheum Dis 2019. doi:10.1136/annrheumdis-2019-215211. [Epub ahead of print: $11 \mathrm{Jul} 2019]$.

2 Henter J-I, Horne A, Aricó M, et al. HLH-2004: diagnostic and therapeutic guidelines for hemophagocytic lymphohistiocytosis. Pediatr Blood Cancer 2007;48:124-31.

3 Hayden A, Park S, Giustini D, et al. Hemophagocytic syndromes (HPSs) including hemophagocytic lymphohistiocytosis (hLH) in adults: a systematic scoping review. Blood Rev 2016;30:411-20.

4 Crayne CB, Albeituni S, Nichols KE, et al. The immunology of macrophage activation syndrome. Front Immunol 2019;10:119. 